\title{
Pd-Catalyzed Hydroamination of Alkoxyallenes with Azole Heterocycles: Examples and Mechanistic Proposal
}

\author{
Ivan Bernar, ${ }^{\dagger}$ Béla Fiser, ${ }^{\ddagger}, \S$ Daniel Blanco-Ania, ${ }^{\dagger}$ Enrique Gómez-Bengoa, ${ }^{*}{ }^{\ddagger}$ and Floris P. J. T. Rutjes ${ }^{*}, \dagger$ \\ ${ }^{\dagger}$ Institute for Molecules and Materials, Radboud University, Heyendaalseweg 135, 6525 AJ Nijmegen, The Netherlands \\ ${ }^{\ddagger}$ Department of Organic Chemistry I, University of the Basque Country (UPV/EHU), P.O. Box 1072, 20080 Donostia-San Sebastián, \\ Spain \\ ${ }^{\S}$ Institute of Chemistry, Faculty of Materials Science and Engineering, University of Miskolc, H-3515, Egyetemváros-Miskolc, \\ Hungary
}

\section{Supporting Information}

ABSTRACT: Palladium-catalyzed regio- and enantioselective addition of azole heterocycles to alkoxyallenes was developed (up to $92 \%$ yields and up to $94 \%$ ee). DFT calculations suggest a new $\mathrm{Pd}(0)$-driven mechanistic pathway proceeding through protonation of the $\mathrm{Pd}$-coordinated allene $\left(4-\mathrm{PdL}_{2}\right)$, which develops a strongly nucleophilic character at the central $\mathrm{C}$ atom.

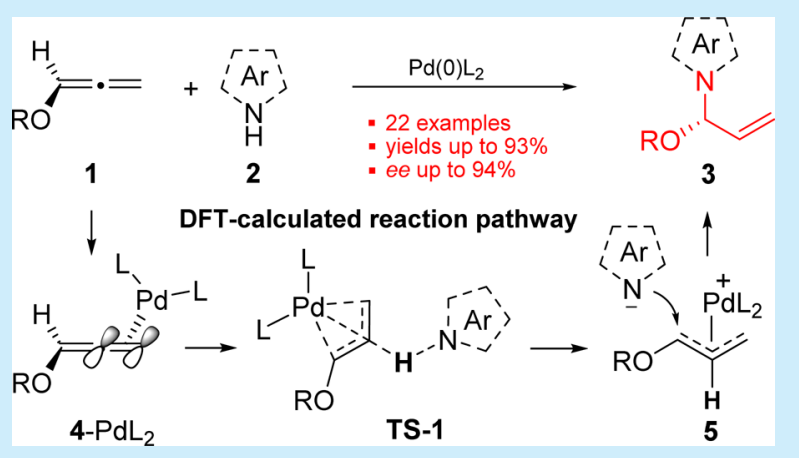

$\mathrm{T}$ he palladium-catalyzed addition of nitrogen nucleophiles to alkoxyallenes is a straightforward conversion to form the corresponding allylic $\mathrm{N}, \mathrm{O}$-acetals under mildly basic conditions. These reactive structures have been used as key intermediates in the synthesis of biologically active heterocycles and natural products. ${ }^{2}$ Examples from our group include the stereoselective synthesis of the natural product $\mathrm{L}$-baikiain ${ }^{2 \mathrm{~b}}$ and a formal total synthesis of the alkaloid quinolizidine $233 \mathrm{~A}^{2 \mathrm{c}, 3}$ To follow up on these results, we envisioned that also aromatic nitrogen nucleophiles, so-called azole heterocycles, would be of particular interest as reactants in such hydroaminations. Thus, we explored the potential of catalytic and enantioselective reactions at the azole nitrogen to gain access to a broad range of chiral, heteroaromatic allylic N,O-acetals 3. Additionally, while palladium hydride species have been invoked as reactive intermediates in most of the hydroamination studies, ${ }^{4,5}$ our current computational investigations argue against such intermediates. We present herewith DFT calculations that suggest an alternative mechanistic pathway that proceeds via coordination of the allene to $\operatorname{Pd}(0)$, and protonation with imidazole of the resulting 4- $\mathrm{PdL}_{2}$ species at the central carbon atom (TS-1). Initial studies to synthesize heteroaromatic allylic $\mathrm{N}, \mathrm{O}$-acetals were guided by previous work from our laboratory on palladium-catalyzed addition of nitrogen nucleophiles to alkoxyallenes. Imidazole (2a) and benzyloxyallene (1a) were used for optimizing the reaction conditions (Table 1). Gratifyingly, the first attempt in the presence of a catalytic amount of $\mathrm{Pd}(\mathrm{OAc})_{2} / \mathrm{dppp}$ (1,3-bis(diphenylphosphino) propane) in refluxing THF provided the desired product 3a in $82 \%$ yield as a single regioisomer (entry 1$)$. Similar results were
Table 1. Reaction Optimization ${ }^{a}$

\begin{tabular}{|c|c|c|c|}
\hline & & $\begin{array}{l}\text { Pd catalyst }(5.0 \mathrm{~mol} \%) \\
\quad \operatorname{dppp}(5.0 \mathrm{~mol} \%)\end{array}$ & \\
\hline & + & $\mathrm{THF}, 60^{\circ} \mathrm{C}, 12 \mathrm{~h}$ & \\
\hline $1 \mathrm{a}$ & & & $3 a$ \\
\hline entry & base & catalyst & yield $^{b}(\%)$ \\
\hline 1 & DBU & $\mathrm{Pd}(\mathrm{OAc})_{2} / \mathrm{dppp}$ & 82 \\
\hline 2 & DBU & $\mathrm{Pd}_{2}(\mathrm{dba})_{3} / \mathrm{dppp}$ & 87 \\
\hline 3 & DBU & $\mathrm{Pd}\left(\mathrm{PPh}_{3}\right)_{4}$ & 85 \\
\hline $4^{c}$ & DBU & $\mathrm{Pd}_{2}(\mathrm{dba})_{3} / \mathrm{dppp}$ & 62 \\
\hline $5^{d}$ & DBU & $\mathrm{Pd}_{2}(\mathrm{dba})_{3} / \mathrm{dppp}$ & 78 \\
\hline 6 & & $\mathrm{Pd}_{2}(\mathrm{dba})_{3} / \mathrm{dppp}$ & 93 \\
\hline
\end{tabular}

${ }^{a}$ Conditions: Pd catalyst $(5 \mathrm{~mol} \%)$, dppp $(5 \mathrm{~mol} \%)$, 1a $(0.3 \mathrm{mmol})$, 2a $(0.36 \mathrm{mmol})$, THF $(3.0 \mathrm{~mL}), 60^{\circ} \mathrm{C}, 12 \mathrm{~h} .{ }^{b}$ Isolated yield. ${ }^{c} 23^{\circ} \mathrm{C}$ ${ }^{d} \mathrm{MeCN}$, reflux.

obtained by changing catalyst, temperature, and solvent (entries 2-5). Unexpectedly, in the absence of additional base and under the optimal reaction conditions $\left(2.5 \mathrm{~mol} \%\right.$ of $\mathrm{Pd}_{2} \mathrm{dba}_{3}$, $5.0 \mathrm{~mol} \%$ of dppp in THF) the reaction went to completion in $4 \mathrm{~h}$ at $60{ }^{\circ} \mathrm{C}$, yielding the desired $\mathrm{N}, \mathrm{O}$-acetal 3a in $93 \%$ yield (entry 6).

Along with these results, different heterocyclic systems containing the azole framework were subjected to the

Received: June 15, 2017

Published: August 8, 2017 
Scheme 1. Scope of $\operatorname{Pd}(0)$-Catalyzed Allylic N,O-Acetal Formation ${ }^{a, b}$

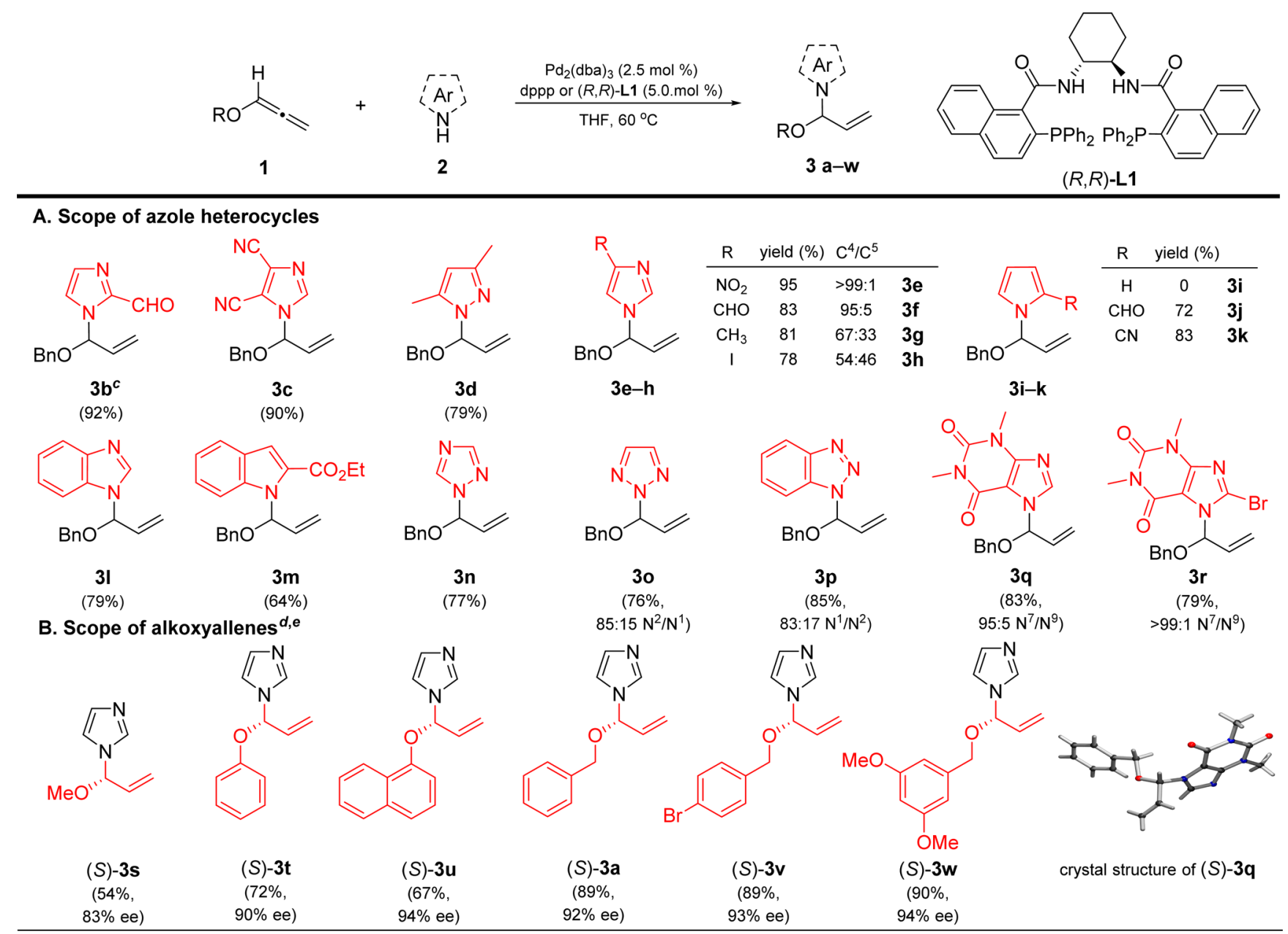

${ }^{a}$ Conditions: $\mathrm{Pd}_{2}(\mathrm{dba})_{3}(2.5 \mathrm{~mol} \%)$, dppp $(5 \mathrm{~mol} \%), 1(0.3 \mathrm{mmol}), 2(0.36 \mathrm{mmol}), \mathrm{THF}(3.0 \mathrm{~mL}), 60{ }^{\circ} \mathrm{C}$ was used. ${ }^{b}$ Isolated yields. ${ }^{c} \mathrm{Carried}$ out on a $1 \mathrm{mmol}$ scale. ${ }^{d}(R, R)-\mathrm{L} \mathbf{1}(5 \mathrm{~mol} \%)$ was used as ligand, DCE $(3.0 \mathrm{~mL}) .{ }^{e}$ The ee values were determined by HPLC analysis.

optimized reaction conditions (Scheme 1A). Generally, the anticipated $\mathrm{N}, \mathrm{O}$-acetals $\mathbf{3 a}-\mathbf{w}$ were obtained in modest to excellent yields (54-92\%). In the case of asymmetrically substituted imidazoles, mixtures of the 4- and 5-substituted isomers $\mathbf{3 e}-\mathbf{h}$ were obtained. Thus, 4-nitroimidazole and imidazole-4-carbaldehyde were converted into C-4 allylic N,Oacetals $3 \mathbf{e}$ and $3 \mathbf{f}$ in good yields with nearly complete regioselectivity. In contrast, 4-methylimidazole and 4-iodoimidazole showed almost no regioselectivity, yielding a close to $1: 1$ mixture of the 4- and 5-substituted isomers $3 \mathrm{~g}$ and $3 \mathrm{~h}$. Remarkably, in the case of pyrrole, only degradation of allene 1a was observed. ${ }^{6}$ Changing the conditions (solvent, temperature, Pd catalysts, addition of base) did not lead to product $3 \mathbf{i}$ either. In contrast, pyrroles substituted with electron-withdrawing groups, in particular, pyrrole-2-carbaldehyde and pyrrole-2-carbonitrile, showed nearly the same reaction rates as imidazole and gave the desired products in good yields ( 72 and $83 \%$ for $3 \mathbf{j}$ and $\mathbf{3 k}$, respectively). Azole heterocycles with multiple $N$-nucleophilic centers also showed good reactivity in the intermolecular addition to benzyloxyallene (1a). To our delight, the corresponding triazole-containing $\mathrm{N}, \mathrm{O}$-acetals 3o,p were obtained in good to excellent yields and excellent regioselectivities. Likewise, when bulky substrates such as theophylline and 2-bromotheophylline were used, the corre- sponding $\mathrm{N}, \mathrm{O}$-acetals $\mathbf{3 q}$ and $3 \mathbf{r}$ were formed with good selectivity.

Next, we examined the asymmetric version of Pd-catalyzed hydroamination of imidazole (2a) with a variety of alkoxyallenes (Scheme 1B). Here, we evaluated several commercially available chiral bisphosphine ligands, solvents, and additives (for detailed information on the optimization, see the Supporting Information). Our strategy was based on the work on Pd- and Rh-catalyzed asymmetric additions onto allenes. ${ }^{5}$ In analogy to this work, Rhee et al. recently reported several successful examples of Pd-catalyzed asymmetric hydroaminations, which opened up a route toward enantioselective allylic $\mathrm{N}, \mathrm{O}$-acetal formation. ${ }^{1 \mathrm{e}-\mathrm{g}, 2 \mathrm{~d}, \mathrm{e}}$ Modifying their procedure and performing the reaction in the presence of $\operatorname{Pd}_{2}(\mathrm{dba})_{3}(2.5$ mol \%) and (R,R)-DACH-naphthyl Trost ligand L1 (5 mol \%), we were pleased to observe that a number of alkoxyallene analogues reacted well with imidazole giving rise to products $(S)-3 \mathbf{s}-\mathbf{w}$ and $(S)-\mathbf{3 a}$, not only in good yields but in most cases also with high enantioselectivities (up to $94 \%$ ee).

To indicate the broader scope and reveal the absolute configuration of the obtained products, we performed the reaction with 1,3-dimethylxantine theophylline and allene (1a), and the crystal structure of the major enantiomer of product $3 \mathbf{q}$ (74\%, 92\% ee) was elucidated. The absolute configuration was assigned to be $S$ in all cases based on the X-ray data of $3 q$ and 
the CD profiles of the other products (see the SI), which is in correspondence with the expected stereochemistry.

The mechanism of the Pd-catalyzed additions of pronucleophiles with relatively acidic protons to allenes has been thoroughly investigated by Trost. ${ }^{5}$ Experimental studies have shown that this process is initiated by oxidative addition of palladium into the acidic $\mathrm{C}-\mathrm{H}$ bond to form a cationic $\mathrm{Pd}-\mathrm{H}$ species $(7$, Scheme 2$)$. This intermediate can readily react with

Scheme 2. Classical Mechanism of the Hydroamination ${ }^{a}$

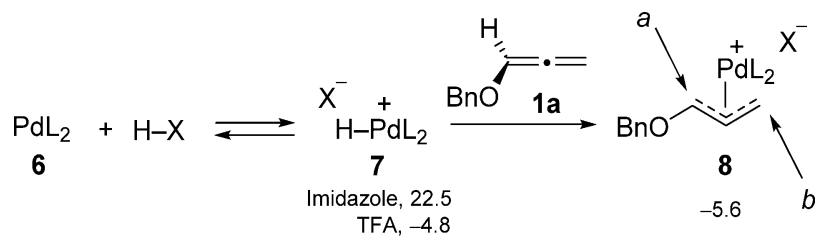

${ }^{a}$ Free energies $(298 \mathrm{~K})$ with respect to 6 are shown in $\mathrm{kcal} / \mathrm{mol}$.

the allene, thereby generating a $\pi$-allylpalladium species (8). Addition of the anion of the pronucleophile to this intermediate through trajectories $a$ or $b$ then forms the products with regeneration of the $\operatorname{Pd}(0)$ catalyst.

Since no studies have been reported on the protonation of low-valent palladium with weak acids (e.g., imidazole), we turned to DFT calculations ${ }^{7}$ to shed light on a plausible mechanism for our alkoxyallene/imidazole reaction and considered initially a pathway similar to that outlined in Scheme 2. Indeed, our preliminary calculations showed that 8 ( $\mathrm{X}=$ imidazolide, $\mathrm{L}_{2}=1,3$-bis(dimethylphosphino) propane, $\mathrm{dmpp}$ ) is a reasonable intermediate for the reaction. Its computed free energy value was $5.6 \mathrm{kcal} / \mathrm{mol}$ lower than the sum of the initial substrates $(6+$ imidazole + allene $1 \mathrm{a}$, Scheme $2)$, and its reaction with the imidazolide nucleophile preferentially occurs through the $a$ trajectory $(8.0 \mathrm{kcal} / \mathrm{mol}$ lower than $b$ ) to form the $\mathrm{N}, \mathrm{O}$-acetal product, in agreement with the experimental findings.
However, some critical inconsistencies were evidenced around the participation of intermediate 7 in the mechanism (Scheme 2) since its existence was incompatible with the following data: (a) A determining preference of $18.9 \mathrm{kcal} / \mathrm{mol}$ for the coordination of $\operatorname{Pd}(0)$ to allene 1a over imidazole (2a) was found (10a vs 9, Figure 1), severely compromising any further participation of palladium species 9 and TS-3 in the mechanism of the reaction. ${ }^{8}$ (b) The formation of $\mathrm{H}-\mathrm{Pd}^{+} \mathrm{X}^{-}$ species of type 7 has been exclusively described for strong $\mathrm{H}-\mathrm{X}$ acids, and the hydride has not been observed when weaker acids were used. ${ }^{9}$ In agreement with these experimental facts, the computed equilibrium between $\operatorname{Pd}(0)$ and trifluoroacetic acid is shifted toward the formation of cationic $\mathrm{H}-\mathrm{Pd}^{+}$species 7 by $4.8 \mathrm{kcal} / \mathrm{mol}$ (Scheme 2), while using imidazole as a proton source, the hydride is disfavored by $22.5 \mathrm{kcal} / \mathrm{mol}$. (c) The combination of factors $\mathrm{a}$ and $\mathrm{b}$ affords an unrealistic energy of $41.1 \mathrm{kcal} / \mathrm{mol}$ for hydride 7 over $10 \mathrm{a}$, and even the formation of other less unstable $\mathrm{Pd}-\mathrm{H}$ species (e.g., 12, see SI) is unreachable by any means (Figure 1$).{ }^{10}$ We can safely state that in these conditions, $\mathrm{H}-\mathrm{Pd}^{+}$species would never form. Therefore, the intriguing findings that intermediates 10a and 8 participate in the mechanism but are at the same time not connected through the cationic $\mathrm{H}-\mathrm{Pd}^{+}$species 7 led us to search for a pathway to connect both intermediates. Gratifyingly, after some computational effort, a new transition state (TS-1) was located for the direct protonation of the Pdcoordinated allene with imidazole with a moderate activation barrier of $19.7 \mathrm{kcal} / \mathrm{mol}$ (Figure 1). ${ }^{11}$ The structure is highly interesting and original and implies that the allene, after coordination to $\operatorname{Pd}(0)$ in $10 a$, becomes sufficiently basic at the central $\mathrm{C}$ atom to deprotonate imidazole.

Indeed, a very high-in-energy local minimum structure (11, $19.1 \mathrm{kcal} / \mathrm{mol}$ higher than 10a) was located during the intrinsic reaction coordinate (IRC) of the transition state TS-1, corresponding to a bidentate coordination mode of allene to palladium with high nucleophilic carbene character. ${ }^{12}$ The carbene-like species 11 is so close in energy $\left(\Delta \Delta G^{\ddagger}=0.6 \mathrm{kcal} /\right.$

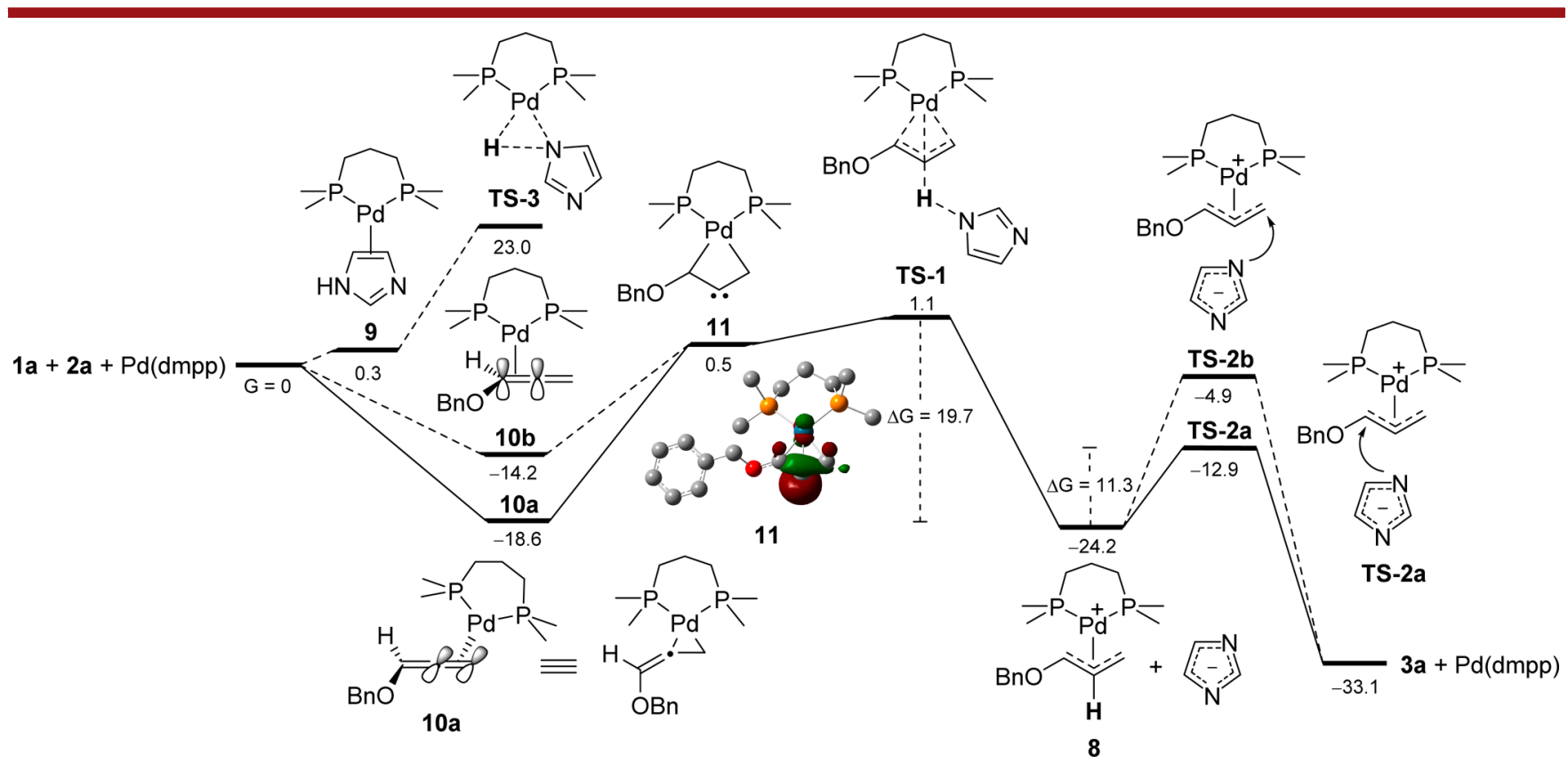

Figure 1. Computed reaction pathway with 3-D representation of the HOMO orbitals for 11. Free energies (298 K) with respect to starting materials are shown in $\mathrm{kcal} / \mathrm{mol}$. 
mol) to the transition state that it could not be considered a stable reaction intermediate, but it is still very informative, revealing that during the protonation trajectory from 10a to TS-1, the allene bends and develops a significant negative charge at the central $\mathrm{C}$ atom. ${ }^{13}$ Finally, the attack of the imidazolide to $\mathbf{8}$ was found to occur through pathway $a$, as in Scheme 2 (TS-2a, Figure 1), with an activation free energy of $11.3 \mathrm{kcal} / \mathrm{mol}$.

In conclusion, we have developed highly effective Pdcatalyzed protocols for the addition of a wide scope of azole heterocycles to alkoxyallenes providing a unique way to synthesize aromatic allylic $\mathrm{N}, \mathrm{O}$-acetals in high yields (up to 95\%) and enantiomeric excesses (up to 94\%). A nonconventional $\mathrm{Pd}(0)$-driven mechanistic pathway was proposed based on the DFT calculations of the studied process. This should be considered as an alternative pathway for nonacidic nucleophiles, where highly favorable coordination of allene to the palladium catalyst followed by the protonation with a week acid forms $\mathrm{Pd}-\pi$-allyl species. Such a process involves a reactive, carbenelike local minimum, which is a crucial link that connects both intermediates. At the same time, acidic nucleophiles, as well as acid/base additives, would rather prefer to form the $\mathrm{Pd}-\pi$-allyl complex through cationic $\mathrm{Pd}-\mathrm{H}$ species. Further studies on trapping the reaction intermediates and understanding the mechanism of this reaction, as well as the application of this methodology in target-orientated synthesis, are currently in progress.

\section{ASSOCIATED CONTENT}

\section{S Supporting Information}

The Supporting Information is available free of charge on the ACS Publications website at DOI: 10.1021/acs.orglett.7b01826.

Experimental procedures, spectroscopic characterizations, crystallographic analyses (CIF), and computational data(PDF)

General methods, complex formation, and Cartesian coordinates (PDF)

X-ray data for compound $(S)-3 \mathbf{q}(\mathrm{CIF})$

\section{AUTHOR INFORMATION}

\section{Corresponding Authors}

*E-mail: enrique.gomez@ehu.es (computational part).

*E-mail: floris.rutjes@ru.nl (experimental part).

Notes

The authors declare no competing financial interest.

\section{ACKNOWLEDGMENTS}

Financial support for this research was provided by the FP7Marie Curie Actions of the European Commission via the ITN ECHONET (MCITN-2012-316379). We also acknowledge technical and human support provided by IZOSGI SGIker of UPV-EHU. Prof. Dr. B. de Bruin and Dr. J. C. Slootweg (University of Amsterdam) are kindly acknowledged for useful suggestions.

\section{REFERENCES}

(1) Selected reports of palladium-catalyzed additions of $\mathrm{N}$ nucleophiles to alkoxyallenes of general formula 4: (a) Desarbre, E.; Merour, J. Y. Tetrahedron Lett. 1996, 37, 43. (b) Kinderman, S. S.; Wekking, M. M. T.; van Maarseveen, J. H.; Schoemaker, H. E.;
Hiemstra, H.; Rutjes, F. P. J. T. J. Org. Chem. 2005, 70, 5519. (c) Donohoe, T. J.; Orr, A. J.; Gosby, K.; Bingham, M. Eur. J. Org. Chem. 2005, 2005, 1969. (d) Donohoe, T. J.; Kershaw, N. M.; Orr, A. J.; Wheelhouse, K. M. P.; Fishlock, L. P.; Lacy, A. R.; Bingham, M.; Procopiou, P. A. Tetrahedron 2008, 64, 809. (e) Kim, H.; Rhee, Y. H. Synlett 2012, 23, 2875. (f) Kim, H.; Rhee, Y. H. J. Am. Chem. Soc. 2012, 134, 4011. (g) Kim, H.; Lim, W.; Im, D.; Kim, D.; Rhee, Y. H. Angew. Chem., Int. Ed. 2012, 51, 12055. (h) Zimmer, R.; Reissig, H.-U. Chem. Soc. Rev. 2014, 43, 2888.

(2) For allylic N,O-acetals as key intermediates in synthesis of some natural compounds: (a) Tjen, K. C. M. F.; Kinderman, S. S.; Schoemaker, H. E.; Hiemstra, H.; Rutjes, F. P. J. T. Chem. Commun. 2000, 699. (b) Kinderman, S. S.; Doodeman, R.; van Beijma, J. W.; Russcher, J. C.; Tjen, K. C. M. F.; Kooistra, T. M.; Mohaselzadeh, H.; van Maarseveen, J. H.; Hiemstra, H.; Schoemaker, H. E.; Rutjes, F. P. J. T. Adv. Synth. Catal. 2002, 344, 736. (c) Kinderman, S. S.; de Gelder, R.; van Maarseveen, J. H.; Schoemaker, H. E.; Hiemstra, H.; Rutjes, F. P. J. T. J. Am. Chem. Soc. 2004, 126, 4100. (d) Kang, S.; Kim, D.; Rhee, Y. H. Chem. - Eur. J. 2014, 20, 16391. (e) Lim, W.; Rhee, Y. H. Tetrahedron 2015, 71, 5939.

(3) Michael, J. P. Nat. Prod. Rep. 2002, 19, 719.

(4) For the mechanism of palladium-catalyzed additions of pronucleophiles to allenes, see: (a) Besson, L.; Goré, J.; Cazes, B. Tetrahedron Lett. 1995, 36, 3857. (b) Yamamoto, Y.; Al-Masum, M.; Asao, N. J. Am. Chem. Soc. 1994, 116, 6019. (c) Yamamoto, Y.; Radhakrishnan, U. Chem. Soc. Rev. 1999, 28, 199. (d) Kamijo, S.; Yamamoto, Y. Tetrahedron Lett. 1999, 40, 1747.

(5) Selected examples of Pd- and Rh-catalyzed asymmetric additions onto allenes: (a) Trost, B. M.; Jäkel, C.; Plietker, B. J. Am. Chem. Soc. 2003, 125, 4438. (b) Trost, B. M.; Simas, A. B. C.; Plietker, B.; Jäkel, C.; Xie, J. Chem. - Eur. J. 2005, 11, 7075. (c) Trost, B. M.; Xie, J.; Sieber, D. J. Am. Chem. Soc. 2011, 133, 20611. (d) Koschker, P.; Breit, B. Acc. Chem. Res. 2016, 49, 1524. (e) Thieme, N.; Breit, B. Angew. Chem., Int. Ed. 2017, 56, 1520.

(6) (3,3-Bis(benzyloxy)prop-1-ene was formed as the major product. This side product is presumably formed after partial degradation of benzyloxyallene 1a followed by addition of released $\mathrm{BnOH}$ to 1 a. For similar results see ref $5 \mathrm{~b}$.

(7) $\mathrm{M} 06 / 6-311+\mathrm{G}^{* *}(\mathrm{SDD})$ level of theory was used in all cases, and for verification purposes, other theoretical levels were applied when necessary.

(8) Species 7 and 10a are the most stable structures among a series of isomeric $\operatorname{Pd}(0)$ complexes with imidazole and allene. The rest of the structures can be found in the Supporting Information.

(9) Hydrido complexes of palladium as key intermediates in the process: (a) Leoni, P.; Sommovigo, M.; Pasquali, M.; Midollini, S.; Braga, D.; Sabatino, P. Organometallics 1991, 10, 1038. (b) Grushin, V. V. Chem. Rev. 1996, 96, 2011. (c) Trost, B. M. Chem. - Eur. J. 1998, 4, 2405. (d) Amatore, C.; Jutand, A.; Meyer, G.; Carelli, I.; Chiarotto, I. Eur. J. Inorg. Chem. 2000, 2000, 1855.

(10) Other different $\mathrm{Pd}(\mathrm{II})$ hydride species (e.g., imidazolide-Pd-H) were also considered, and can be found in the Supporting Information. None of them is operative.

(11) Different computational levels show consistent activation energy values for TS-1: M06/6-311+G**(SDD): $19.7 \mathrm{kcal} / \mathrm{mol}$; M06/ def2TZVPP: $19.0 \mathrm{kcal} / \mathrm{mol}$; B3LYP-D3/6-31G**(LANL2DZ): 17.8 $\mathrm{kcal} / \mathrm{mol}$. CPCM-MeCN solvent model was used in all cases.

(12) For comparative Fukui nucleophilicity indexes and HOMO energies of 10a and 11, see the Supporting Information.

(13) The exact nature of structure 11, which could be a local minimum computational artifact along the reaction trajectory, does not compromise the low activation energy from 10a to TS-1. At some point during the formation of TS-1, the allene-Pd system should reorganize as in $\mathbf{1 1 .}$ 